\title{
Rancang Bangun Aplikasi Pengawasan Dan Pengendalian Komputer Laboratorium Multimedia STMIK Palangkaraya
}

\author{
Sam'ani \\ Ilmu Komputer Universitas Muhammadiyah Palangkaraya \\ Alamat : Jl. RTA. Milono Km. 1,5 Palangkaraya, Kalimantan Tengah \\ E-mail : sam.umpalangkaraya@gmail.com
}

\begin{abstract}
ABSTRAK
Kemajuan teknologi dan sistem pengawasan komputer pada saat ini telah memberikan suatu sumbangan positif yang signifikan disegala bidang untuk menunjang dan meningkatkan kinerja suatu sistem. Salah satu kemajuan teknologi dibidang komputer adalah pengawasan dan pengendalian komputer. Sistem pengawasan dan pengendalian komputer yang digunakan pada laboratorium komputer di Sekolah Tinggi Manajemen Informatika dan Komputer (STMIK) Palangkaraya masih menggunakan sistem yang berbayar atau harus membeli terlebih dahulu untuk dapat menggunakannya pada setiap ruangan laboratorium komputer, sehingga tidak semua ruangan laboratorium komputer dapat dilakukan pengawasan menggunakan sistem tersebut karena tidak sedikit biaya yang harus dikeluarkan untuk membeli sistem tersebut. Oleh karena itu untuk melakukan pengawasan terhadap semua ruangan laboratorium STMIK Palangkaraya dibangun sistem pengawasan dan pengendalian komputer yang dapat digunakan secara gratis (free). Metode pengembangan perangkat lunak yang digunakan adalah metode System Development Life Cycle (SDLC) dengan pendekatan pengembangan model air terjun (waterfall). Bahasa pemrograman yang digunakan yaitu Microsoft Visual Basic. Berdasarkan hasil ujicoba terhadap sistem yang dibangun menghasilkan semua proses dan fasilitas yang terdapat dalam sistem berjalan sesuai dengan butir pengujian yang telah ditetapkan.
\end{abstract}

Kata Kunci : Pengawasan dan pengendalian Komputer, laboratorium komputer, Waterfall

\section{ABSTRACT}

The progress of technology and computer surveillance systems at this time has provided a significant positive contribution in all fields to support and improve the performance of a system. One of the technological advances in the field of computers is computer monitoring and control. Computer monitoring and control systems used in computer laboratories at the College of Information and Computer Management (STMIK) Palangkaraya still use a paid system or must first purchase to be able to use it in every computer laboratory room, so that not all computer laboratory rooms can be monitored using the system because there are not a few costs to purchase the system. Therefore, to supervise all the STMIK Palangkaraya laboratory rooms, a computer monitoring and control system is built that can be used free of charge. The software development method used is the System Development Life Cycle (SDLC) method with a waterfall model development approach. The programming language used is Microsoft Visual Basic. Based on the results of tests on the system that was built to produce all the processes and facilities contained in the system running in accordance with the test items that have been set.

Keywords: Computer supervision and control, computer laboratory, Waterfall

\section{PENDAHULUAN}

Dengan semakin seringnya penggunaan dan berbagai macam hal yang dapat dilakukan di dalam sebuah laboratorium komputer serta terbatasnya petugas laboran yang ada, maka perlu adanya sistem pengawasan dan pengendalian dalam penggunaan laboratorium komputer secara menyeluruh, misalnya dalam Kegiatan Praktikum, 
Kegiatan Ujian dan kegiatan-kegiatan lainnya yang menggunakan komputer.

Sekarang ini banyak sekali ditemui aplikasi pengawasan yang dapat digunakan dalam sebuah laboratorium, akan tetapi diantara berbagai aplikasi tersebut ada aplikasi yang tidak serta merta digunakan secara bebas karena berbagai fitur-fitur yang diberikan didalam aplikasi tersebut, misalnya aplikasi davitech untuk pembelajaran bahasa pada laboratorium komputer STMIK Palangkaraya, agar pihak laboratorium dapat menggunakan aplikasi ini untuk melakukan pengawasan dalam proses kegiatan-kegiatan diatas, pihak laboratorium harus membayar dengan tidak sedikit biaya yang harus dikeluarkan untuk aplikasi ini.

Oleh karena itulah akan dibangun sebuah sistem pengawasan dan pengendalian penggunaan komputer pada laboratorium STMIK Palangkaraya dapat digunakan secara bebas dan gratis tanpa harus membeli terlebih dahulu untuk menggunakannya.

\section{TINJAUAN PUSTAKA}

2.1 Penelitian yang dilakukan oleh Yoga Nurjaman dkk (2012) dengan judul Pengembangan Sistem Remote Access Jaringan Berbasis Client-Server, menjelaskan bagaimana sistem remote access dibuat bekerja untuk memantau komputer dalam sebuah jaringan dengan beberapa fitur-fitur yang cukup banyak. Penelitian yang penulis hasilkan berupa aplikasi remote dan monitoring komputer untuk laboratorium STMIK Palangkaraya, dengan beberapa fitur yang diperlukan untuk melakukan pengawasan penggunaan komputer serta keamanan akses ke komputer dan data yang digunakan untuk mengakses komputer client tersimpan kedalam sistem pengelolaan database MySql Server sehingga dapat diakses dari komputer lain.

2.2 Penelitian yang berjudul Pemantauan Jaringan Komputer dengan DNS Server Berbasis Routing Statis Menggunakan Wireshark (Widodo Sarono : 2012) berhasil memantau kinerja jaringan komputer dengan aplikasi penganalisis jaringan wireshark untuk analisis, pengembangan protokol komunikasi, membuat tabel routing dan mengkonfigurasi router.

2.3 Dalam penelitian berjudul Rancang Bangun Aplikasi Monitoring Perangkat Keras Komputer Menggunakan Windows Query Language (Paulus Lucky dkk, 2016) berhasil membuat aplikasi monitoring memanfaatkan teknologi web service dan Windows Query Language untuk memudahkan dokumentasi informasi aset laboratorium yang melibatkan spesifikasi perangkat komputer, seperti data perangkat keras, sistem operasi hingga data kondisi kelayakan perangkat tersebut.

\section{METODE PENELITIAN}

Penelitian ini menggunakan metode pengembangan perangkat lunak System Development Life Cycle (SDLC) dengan pendekatan pengembangan model air terjun (waterfall) sebagaimana pada gambar berikut :

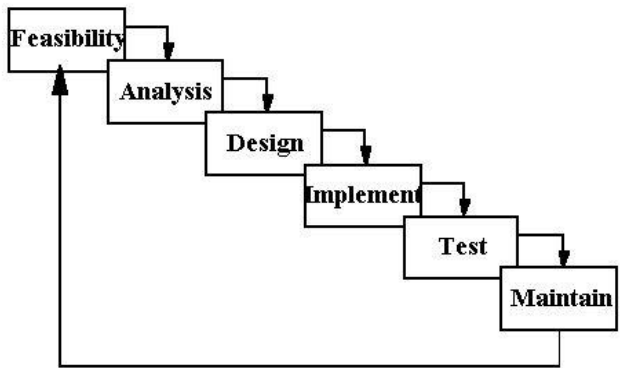

Gambar 1. Kerangka Kerja Pengembangan Sistem Informasi $(S D L C)$

Bahasa pemrograman yang digunakan yaitu Microsoft Visual Basic dengan MySQL Server sebagai databasenya.

\section{HASIL DAN PEMBAHASAN}

4.1 PERANCANGAN SISTEM

\subsubsection{Use Case Diagram}

Dalam Use Case ini digambarkan proses mengatur user access dan IP server agar sistem server dapat mengkases ke sistem client, dan sistem client dapat mengirimkan panggilan ke sistem server melalui IP yang di inputkan.

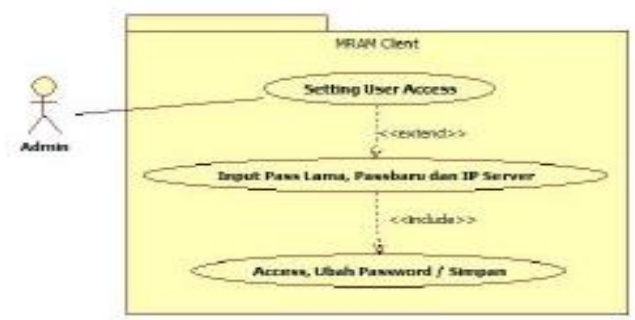

Gambar 2. Use Case Diagram 


\subsubsection{Class Diagram}

Class Diagram adalah suatu diagram yang memperlihatkan atau menampilkan struktur dari sebuah sistem,sistem tersebut akan menampilkan sistem kelas dan relasi antar kelasnya. Berikut ini adalah class diagram pada sistem yang akan dibuat :

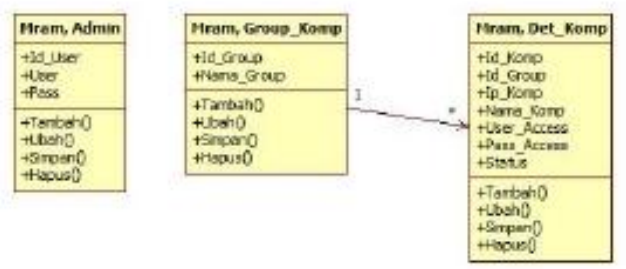

Gambar 3. Class Diagram

\subsection{ANTARMUKA SISTEM}

Antarmuka sistem yang dihasilkan terdiri dari 2 (dua), yaitu :

4.2.1 Antarmuka utama Client untuk User

Antarmuka ini terdiri dari 2 pilihan yaitu Panggil untuk memanggil sistem server dan Setting digunakan untuk mengakses sistem client.

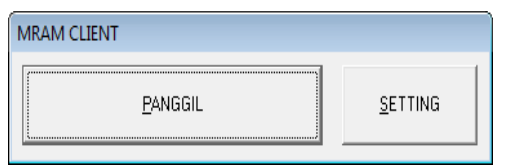

Gambar 4. Antarmuka Utama Client

\subsubsection{Antarmuka utama Sistem Server}

Antarmuka sistem server ini terdiri dari beberapa textbox yang memiliki pointpoint untuk mengatur koneksi database, diantaranya yaitu ip server database, nama database, port database server, username dan password digunakan untuk mengkases ke server database. Jika baru pertama kali menginstall bisa menggunakan username "admin" dan password "admin".

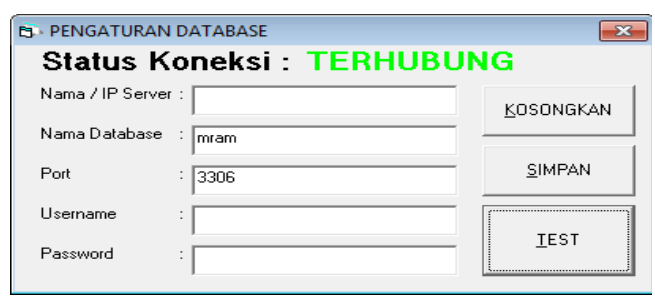

Gambar 4. Antarmuka sistem server

Pada menu sistem server ini terdapat beberapa sub menu, yaitu :
1) Kelola data admin digunakan untuk mengelola data admin, diantaranya yaitu menambah data, mengubah data dan menghapus data.

2) Kelola Data Group Komputer untuk mengelola data group komputer yang nantinya akan digunakan untuk mengelompokkan data-data komputer menjadi satu kedalam group-group yang telah tersimpan

3) Kelola Data Komputer digunakan untuk mengakses sistem client. Semua kegiatan sistem server akan banyak dilakukan pada sub menu ini, yaitu : Monitoring Desktop untuk mengawasi kegiatan yang dilakukan oleh komputer yang terhubung; Obrolan Teks untuk melakukan komunikasi kepada pengguna sistem client; Remote Task Manager untuk melakukan kelola aplikasi yang berjalan di komputer client; Remote File Manager untuk mengelola filefile yang ada didalam komputer client; Remote Control untuk mengontrol komputer dengan pilihan yang ada didalamnya.

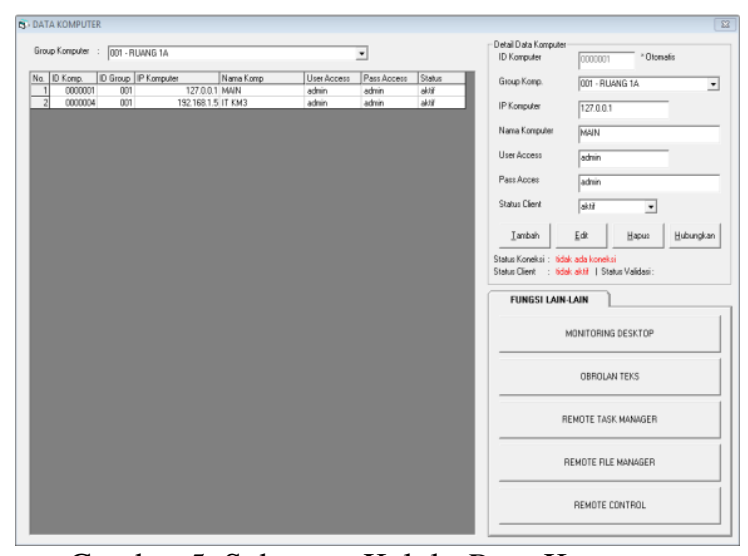

Gambar 5. Submenu Kelola Data Komputer

\subsection{PENGUJIAN SISTEM}

Pengujian dilakukan pada laboratorium multimedia STMIK Palangkaraya yang terdiri dari 20 unit komputer. Pengujian terbagi 2, yaitu :

\subsubsection{Pengujian Client untuk User}

Hasil pengujiannya dapat dilihat pada tabel berikut : 
Tabel 1. Hasil Pengujian Client

\begin{tabular}{lll}
\hline Kelas Uji & \multicolumn{1}{c}{ Butir Uji } & Hasil Pengujian \\
\hline $\begin{array}{l}\text { Pengujian } \\
\text { Tampilan }\end{array}$ & $\begin{array}{l}\text { Pada tampilan ini } \\
\text { terdapat menu atau }\end{array}$ & $\begin{array}{l}\text { Menu Panggil } \\
\text { dan Setting dapat } \\
\text { dijalankan }\end{array}$ \\
Utama & tombol Panggil dan & \\
Program & Setting, Pengguna User & \\
Client & hanya dapat & \\
& menggunakan menu & \\
& Panggil, sedangkan Menu & \\
& Setting untuk pengguna & \\
Pengujian & Admin & \\
untuk & Pada tampilan ini & User access \\
tampilan & untuk mengubah user & dapat dirubah \\
Setting & access dan ip server yang & dapat dipanggil \\
User & digunakan oleh pengguna & \\
Access & user untuk memanggil & \\
& server & \\
\hline
\end{tabular}

\subsubsection{Pengujian Sistem Server}

Hasil pengujiannya dapat dilihat pada tabel berikut :

Tabel 2. Hasil pengujian Sistem Server

\begin{tabular}{|c|c|c|}
\hline Kelas Uji & Butir Uji & Hasil Pengujian \\
\hline $\begin{array}{l}\text { Pengujian } \\
\text { untuk } \\
\text { pertama } \\
\text { kali } \\
\text { membuka } \\
\text { aplikasi }\end{array}$ & $\begin{array}{l}\text { Sistem akan } \\
\text { menampilkan } \\
\text { form sflash dan } \\
\text { mengecek } \\
\text { koneksi database, } \\
\text { jika koneksi gagal } \\
\text { maka sistem akan } \\
\text { menampilkan } \\
\text { form setting } \\
\text { database, jika } \\
\text { koneksi berhasil } \\
\text { maka sistem akan } \\
\text { menampilkan } \\
\text { form login }\end{array}$ & Sesuai dengan Butir Uji \\
\hline $\begin{array}{l}\text { Pengujian } \\
\text { untuk } \\
\text { form } \\
\text { setting } \\
\text { database }\end{array}$ & $\begin{array}{l}\text { Memilih tombol } \\
\text { test untuk mecoba } \\
\text { pengaturan yang } \\
\text { telah tersimpan, } \\
\text { menginputkan } \\
\text { pengaturan dan } \\
\text { menyimpan }\end{array}$ & Sesuai dengan Butir Uji \\
\hline $\begin{array}{l}\text { Pengujian } \\
\text { untuk } \\
\text { form login }\end{array}$ & $\begin{array}{l}\text { Menginputkan } \\
\text { username dan } \\
\text { password dan } \\
\text { memilih tombol } \\
\text { login }\end{array}$ & Sesuai dengan Butir Uji \\
\hline $\begin{array}{l}\text { Pengujian } \\
\text { untuk } \\
\text { form } \\
\text { rekam } \\
\text { monitor }\end{array}$ & $\begin{array}{l}\text { Form ini } \\
\text { memiliki } \\
\text { beberapa tahapan } \\
\text { sebelum memulai } \\
\text { merekam, yaitu } \\
\text { memilih ukuran } \\
\text { rekaman, } \\
\text { kecepatan } \\
\text { rekaman, mode } \\
\text { lambat dan } \\
\text { mouse, mulai } \\
\text { rekam, pause, } \\
\text { stop dan simpan }\end{array}$ & Sesuai dengan Butir Uji \\
\hline Pengujian & Form kelola data & Sesuai dengan Butir Uji \\
\hline
\end{tabular}

\begin{tabular}{lll}
\hline Kelas Uji & \multicolumn{1}{c}{ Butir Uji } & Hasil Pengujian \\
\hline untuk & admin akan & \\
form & menampilkan & \\
kelola & $\begin{array}{l}\text { data admin dan } \\
\text { data }\end{array}$ & \\
dapat di tambah, & \\
& ubah, hapus dan & \\
disimpan & \\
Pengujian & Form kelola data & Sesuai dengan Butir Uji \\
untuk & group & \\
form & menampilkan & \\
kelola & data group yang & \\
data & dapat di tambah, & \\
group & ubah, hapus dan & \\
komputer & disimpan & \\
\hline
\end{tabular}

\begin{tabular}{lll}
\hline \multicolumn{1}{c}{ Kelas Uji } & \multicolumn{1}{c}{ Butir Uji } & $\begin{array}{c}\text { Hasil } \\
\text { Pengujian }\end{array}$ \\
\hline $\begin{array}{l}\text { Pengujian } \\
\text { untuk } \text { form } \\
\text { kelola data }\end{array}$ & $\begin{array}{l}\text { Form kelola data komputer } \\
\text { menampilkan data komputer }\end{array}$ & $\begin{array}{l}\text { Sesuai } \\
\text { dengan }\end{array}$ \\
yang dapat di tambah, ubah, & Butir Uji
\end{tabular}

komputer

hapus dan simpan, didalam

form ini juga terdapat

beberapa pilihan lain yang

dapat digunakan jika sistem

client telah dihubungkan

dengan sistem server, pilihan

tersebut di antaranya yaitu

monitoring komputer,

obrolan teks, remote task

manager, remote control dan

remote file manager

Pengujian Form monitoring komputer

untuk form

minitoring

komputer

akan menampilkan gambar

yang diambil dari monitor

komputer client yang

Pengujian

untuk form

obrolan teks

terhubung

Form obrolan teks dapat

mengirim pesan ke sistem

client jika sistem client telah

terhubung, didalam form ini

tedapat pilihan untuk

merubah nama pengirim dan

log pesan ditampilkan pada

box pesan

Pengujian untuk form remote task

Form remote task manager

akan menampilkan list

aplikasi yang berjalan pada

komputer client yang dapat

dihentikan, dan admin dapat

menjalankan aplikasi baru

dengan mengisi source

aplikasi dan memilih tombol jalankan

Pengujian

untuk form

Form remote control akan

remote control mpilkan banyak pilihan

yang dapat digunakan oleh

admin, setiap tombol yang

dipilih oleh admin sistem

server akan mengirim

perintah ke sistem client

untuk di kerjakan oleh

sistem client

Sesuai

dengan

Butir Uji

Sesuai

dengan

Butir Uji

Sesuai

dengan

Butir Uji

Bu

dengan

Butir Uji

\begin{tabular}{lll}
\multicolumn{1}{c}{ Kelas Uji } & \multicolumn{1}{c}{ Butir Uji } & \multicolumn{1}{c}{ Hasil Pengujian } \\
\hline $\begin{array}{l}\text { Pengujian } \\
\text { untuk form } \\
\text { remote file }\end{array}$ & $\begin{array}{l}\text { Form remote file } \\
\text { manager akan } \\
\text { menampilkan list }\end{array}$ & Sesuai dengan Butir \\
\hline
\end{tabular}




\begin{tabular}{ll}
\hline manager & drive yang ada \\
pada komputer & client, dan akan \\
menampilkan list & folder dan file \\
sesuai dengan & drive yang \\
dipilih, file dan & folder tersebut \\
dapat di \\
download, \\
dihapus, dilihat \\
informasinya dan \\
dijalankan, dan \\
admin dapat \\
mengupload file \\
ke komputer \\
client \\
\hline
\end{tabular}

Suryo Guritno, Sudaryono, Untung Raharja. 2011. Theory and Application of IT Research. Yogyakarta : Penerbit ANDI

\section{KESIMPULAN}

5.1 Telah dapat dirancang dan dibangun aplikasi Pengawasan Dan Pengendalian Komputer Laboratorium Multimedia STMIK Palangkaraya dengan bahasa pemrograman Visual Basic 2010.

5.2 Berdasarkan hasil pengujian terhadap keseluruhan sistem diperoleh hasil yang sesuai dengan butir pengujian yang telah ditetapkan.

\section{ACUAN REFERENSI}

Paulus Lucky Tirma Irawan, Abdurrahman Kamil Dhermawan, Hendry Setiawan. 2016. Rancang Bangun Aplikasi Monitoring Perangkat Keras Komputer Menggunakan Windows Query Language. Jurnal Kinetik. Vol. 1 No. 3 November 2016, Hal. 155-162. ISSN : 2503-2259. E-ISSN : 2503-2267.

Sarono Widodo. 2012. Pemantauan Jaringan Komputer dengan DNS Server Berbasis Routing Statis Menggunakan Wireshark. Jurnal Teknik Elektro. Vol. 1 No. 2 Agustus 2012 : 1-7. ISSN : 2252-4908. Semarang : Politeknik Negeri Semarang.

Yoga Nurjaman, Dhami Djohar Dhamiri, Ate Susanto. 2012. Pengembangan Sistem Remote Access Jaringan Berbasis ClientServer. Jurnal Algoritma. Vol. 09 No. 07 2012. ISSN : 2302-7339. Garut : Sekolah Tinggi Teknologi Garut.

\section{DAFTAR PUSTAKA}

Adi Nugroho. 2009. Rekayasa Perangkat Lunak Menggunakan UML dan Java. Yogyakarta : Penerbit Andi.

Roger S. Pressman. 2012. Rekayasa Perangkat Lunak Pendekatan Praktisi Buku Satu (Edisi 7). Yogyakarta : Penerbit ANDI. 